\title{
Slicing Crystalline Silicon Wafer by Deep Subsurface Laser Processing and Selective Chemical Etching
}

\author{
Mona Zolfaghari Borra ${ }^{1,2}$, Hisham Nasser ${ }^{1}$, Emine Hande Ciftpinar ${ }^{1,2}$, Ahmet Turnali ${ }^{3}$, Petro Deminskyi ${ }^{3}$, \\ Tahir Colakoglu' ${ }^{1}$, Onur Tokel ${ }^{3}$, Fatih Omer Ilday ${ }^{3}$, Ihor Pavlov ${ }^{1,4}$, Rasit Turan ${ }^{1,2,4}$, Alpan Bek ${ }^{1,2,4}$ \\ 1. The Center for Solar Energy Research and Applications (GÜNAM), Middle East Technical University, 06800, Ankara, Turkey \\ 2. Micro and Nanotechnology Graduate Program, Middle East Technical University, 06800, Ankara, Turkey \\ 3. Department of Physics, I. D. Bilkent University, 06800, Ankara, Turkey \\ 4. Department of Physics, Middle East Technical University, 06800, Ankara, Turkey
}

In this work, we demonstrate use of laser-induced silicon slicing (LASIS) technique to fabricate crystalline silicon (c-Si) slices [1]. In LASIS method, a nanosecond-pulsed fiber laser operating at $1.55 \mu \mathrm{m}$ wavelength, focused deep in Si subsurface induces structural modifications near the focal point due to multiphoton absorption. The raster scan of the focal position inside of the sample, positioned in cross-sectional plane with respect to laser beam, produces a quasi-2D modified Si region. The modified Si region is then etched by cupper nitrite $\left(\mathrm{Cu}\left(\mathrm{NO}_{3}\right)_{2}\right)-$ based selective chemical etchant which selectively targets the laser-modified regions. In order to achieve high etch rate, smooth and defect-free surface; different concentrations of etchant components and etch durations were investigated.
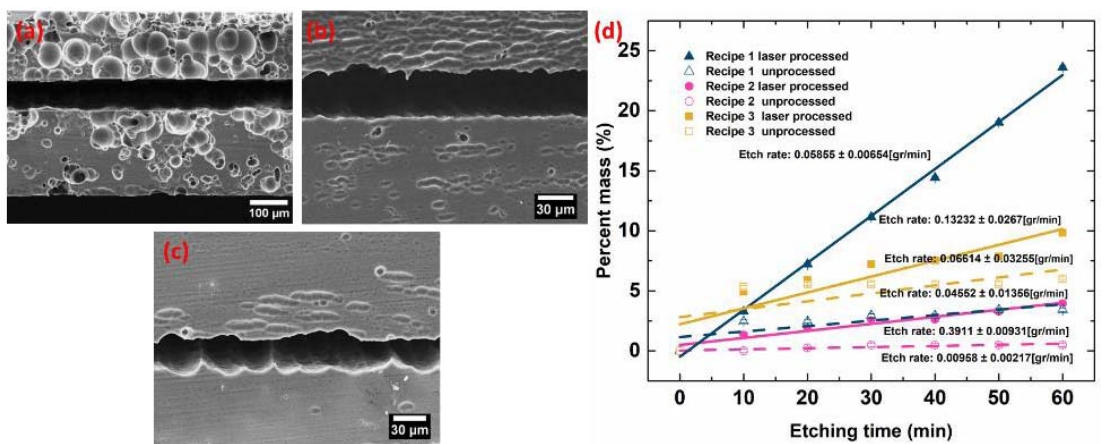

Fig. 1 (a) Cross-sectional SEM images of laser-processed and chemically treated c-Si with different selective etchant recipes: 1 (a), 2 (b), 3 (c). Percent mass as a function of etch duration is shown in (d).

Figures 1 (a-c) display effect of each etch recipe on the morphology of laser-modified regions together with non-modified Si regions. Figure 1(d) shows the percent mass, which is defined as the ratio of the etched mass over the total mass, as a function of etch duration. It can be seen that the etch rate difference between laser processed and unprocessed regions for recipe 1 is higher than that of recipes 2 and 3. On the one hand, using a high $\mathrm{HF}$ concentration in recipe 1 resulted in more defective surface (see Figure 1 (a) /Recipe 1), and reducing the amount of HF resulted in less defect regions (see Figure 1 (b) /Recipe 2). On the other hand, increasing the concentrations of $\mathrm{CH}_{3} \mathrm{COOH}$ and $\mathrm{Cu}\left(\mathrm{NO}_{3}\right)_{2}$ with moderate amount of $\mathrm{HF}$ resulted in least fraction of defect regions associated with increasing etch rate (see Figure 1 (c) and (d)/Recipe 3). Figure 2 shows cross-sectional SEM images of laserprocessed c-Si wafer at different stages.
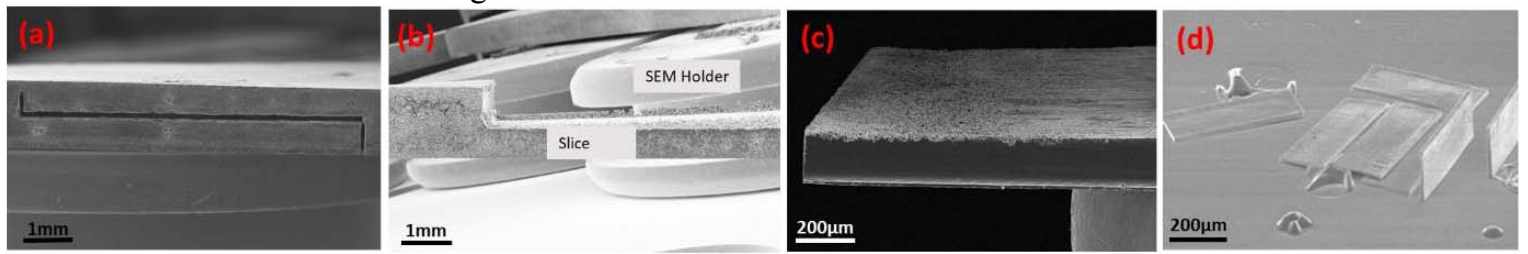

Fig. 2 Cross-sectional SEM images of laser-processed c-Si wafer at different stages: after 20 minutes etching (a), slice formation after 3 hours etching (b), (c), and (d).

Obtained c-Si slices can be utilized in various applications such as photovoltaic solar cells, Si based optoelectronic devices, and photonic crystals.

\section{References:}

[1] O. Tokel, A. Turnalı, G. Makey, P. Elahi, T. Colakoğlu, E. Ergeçen, Ö. Yavuz, R. Hübner, M. Z. Borra, I. Pavlov, A. Bek, R. Turan, D. K. Kesim, S. Tozburun, S. Ilday, F. O. Ilday "In-chip microstructures and photonic devices fabricated by nonlinear laser lithography deep inside silicon" Nature Photonics 11, 639 (2017) 